\title{
Investigating the granger causality relationship between the consumption of different oil products and economic growth in Iran
}

\author{
Kiumars Shahbazi \\ Department of Economics, Urmia University, Urmia, Iran \\ E-mail:k.shahbazi@urmia.ac.ir
}

\begin{abstract}
In light of the recent implementation of subsidy reform plan and the elimination of subsidies for energy carrier prices and, in particular, for oil product prices in Iran, and the pressing need for providing clearer and more effective policy guidelines to help advance the plan, the present study is an attempt to explore the relationship between the consumption of different oil products and economic growth. This study primarily seeks to determine whether a Granger causality relationship exists between the consumption of different oil products and economic growth. And, if so, is it unidirectional or bidirectional? To answer the above questions, the author has applied vector autoregressive and vector error correction model (VECM), using quarterly data from 1988 to 2008. The results indicate that, in short-run, none of oil products consumption stimulates economic growth. But the economic growth Granger causes the consumption of gas oil and gasoline. There is also a weak Granger causality from economic growth to consumption of fuel oil and kerosene. There is no relationship between economic growths and liquid gas. In the long run, there exist a two-way Granger causality relationship between fuel oil consumption and economic growth and a one-way Granger causality relationship from economic growth to the consumption of gas oil and, there is not any relationship between the consumption of other products and economic growth. The results suggest that the reduction of oil products consumption (except fuel oil consumption), due to price increases resulting from removal of subsidies, will not negatively affect the economic growth and, hence, we can pursue the subsidy reform plan on oil products without decelerating economic growth.
\end{abstract}

Keywords: Consumption of oil products; Economic growth; Granger causality; VAR; VECM

\section{Introduction}

Nowadays the crucial role played by energy as a main factor contributing to the production of products and services is undeniable. Coupled with two other important factors, i.e., labor and capital, its contribution to the economic growth of a country is highly significant. Small wonder, then, a great number of empirical studies have been done on it. As far as macroeconomics is concerned, apart from labor and capital, energy is considered as a key factor of production. Given that energy, especially oil, is the driving force of any productive activity, it has a special place in economic growth and development. Our ever-increasing dependence on energy resources has further elevated their status as determining factors in economic growth and development. Hence, examining the causal relation between energy consumption and economic growth has attracted much interest in economic [1]. Despite numerous studies about the relationship between energy consumption and economic growth in Iran, the effect of the consumption of different oil products on economic growth has not yet been done. Therefore, it is necessary to specify the causal relationship between energy consumption and economic growth, which involves different and important policy implications for economy and energy policymakers. In this regard, and according to the recent implementation of subsidy reform plan primarily intended to eliminate subsidies for energy carrier prices and, in particular, for oil product prices, the present study is an attempt to explore the relationship between the consumption of different oil products and economic growth in order to give clearer and more effective policy guidelines to help advance the plan. This study primarily seeks to determine whether or not a Granger causality relationship exists between the consumption of different oil products and economic growth in Iran. And, if so, is it unidirectional or bidirectional? To answer the above questions, the author has applied vector autoregressive (VAR) and vector error correction model (VECM), using quarterly data from 1988 to 2008. 
The remainder of this paper is organized as follows: Section 2 focuses on the trends in consumption of different oil products. Section 3 reviews the literature on the energy-growth nexus. Then, section 4 presents the Data, methodology and empirical results. I'll then provide the policy implications and give conclusions in Section 5.

\section{Trends in consumption of different oil products}

Figure 1 shows the Trends in consumption of different oil products in thousand barrels per day from 1988 to 2008 . As can be seen, gas oil and liquid gas accounted for the most and the least consumption levels respectively. Over the period, average daily consumption amount of gas oil, fuel oil, gasoline, kerosene, and liquid gas is 381.7, 233, 238.3, 160.3 , and 49.5 million barrels respectively, with their average annual growth by $2.5 \%, 2.7 \%, 5.9 \%, 0.5 \%$, and $-1.4 \%$ respectively. During this 20-year period, overall, gas oil (35.98\%) was by far the most popular of all oil products in terms of consumption level, rather distantly followed by fuel oil $(22.1 \%)$ and gasoline $(21.92 \%)$. Liquid gas, on the other hand, was the least popular constituting only $4.74 \%$. The consumption of gasoline overtook that of fuel oil from 2001 on, securing the second place in terms of consumption share as compared to the other oil products (Table 1).

Gas oil can be used for a wide variety of purposes: in transportation for supplying fuel for diesel engines; in agriculture for supplying fuel for agricultural machinery and irrigation pumps; in industry for supplying fuel for industrial machinery and equipment; in power plants for supplying fuel to generate electrical energy; or in domestic and commercial sectors for supplying fuel for heat-producing appliances and for heating water. The transportation sector is the major consumer of gas oil in Iran, accounting for around 53\% of total oil product consumption [14, p. 190].

Regarding the consumption level of fuel oil, power plants consume the largest share of fuel oil for producing electricity. Fuel oil is also used in transportation for supplying fuel for ships. Industries and mines, transportation, and commercial sector make up around $84 \%, 4.5 \%$, and $7.5 \%$ of the consumption of this product respectively $[15$, p. 96$]$.

Transportation also represents the biggest user of gasoline, accounting for over $99.2 \%$ of the total consumption. Rapid increases in car production and demand in recent decades, high average age of cars and thus their low performance, high fuel consumption of domestic cars with older technology used in their production are the major reasons for increased consumption in Iran's transportation sector [14, p. 185].

Liquid gas is mainly used in areas which are not equipped with a gas transmission system yet. According to Figure 1, liquid gas consumption has shown a declining trend from 2005 on, the reasons of which can be the replacement of natural gas with liquid gas in domestic, commercial, industrial, public and other sectors; public transportation infrastructure development; development of suburban rail transport; and development of CNG-burning vehicles.

Figure 1 also indicates that kerosene consumption saw a declining trend from 1993 on. Among others, the decline in the popularity of kerosene can be put down to the expansion of gas and electric power networks throughout the country and a larger number of households accessing these carriers. The major consumers of kerosene are domestic, public and commercial sectors respectively. Research in this respect has found an annual average kerosene consumption of 413 liters per family. Cooking, heating and lighting account for the highest rates of kerosene consumption [14, p. 190].

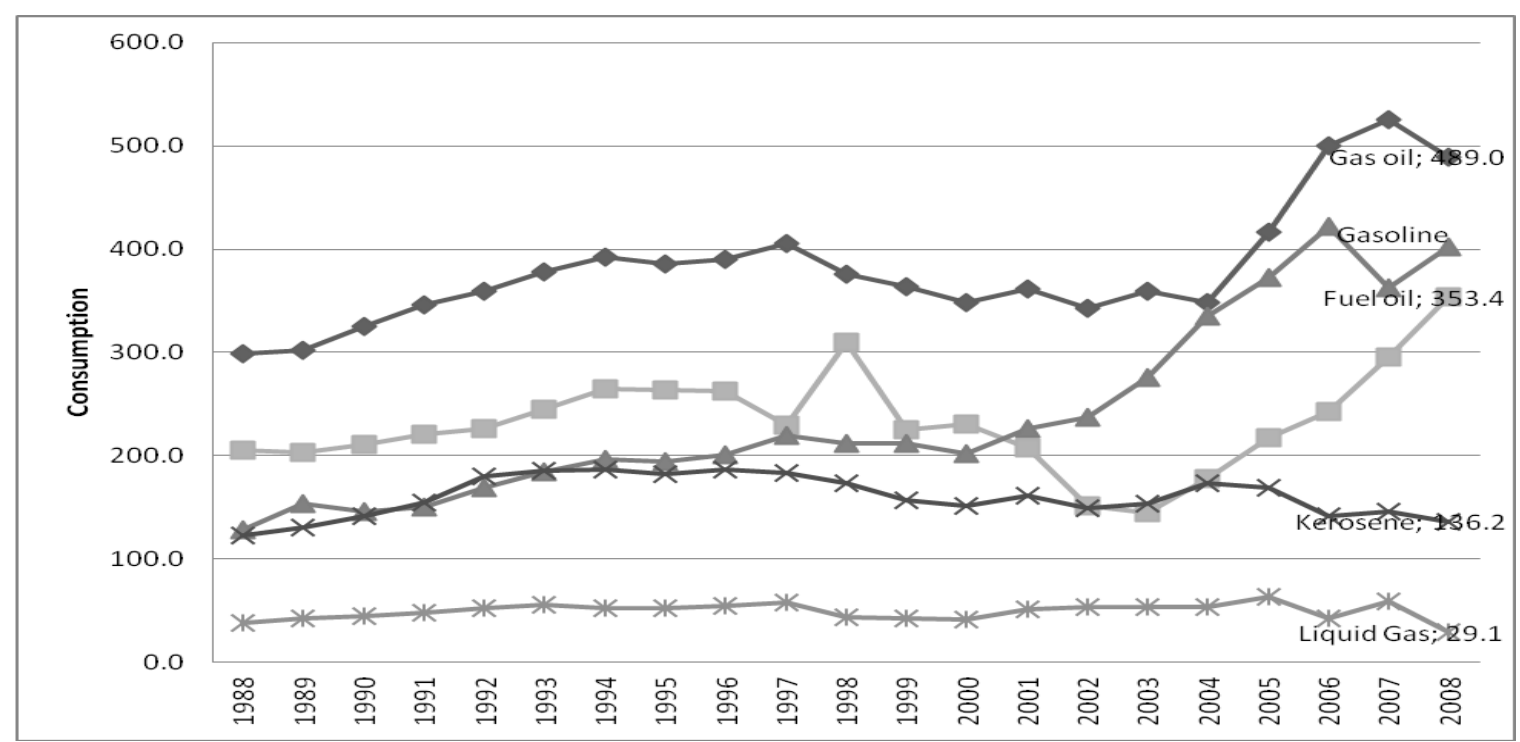

Fig. 1: Trends in Iran's consumption of different oil products in thousand barrels per day from 1988 to 2008 Source of Data: Central Bank of Iran 
Table 1: Trends in Iran's consumption of different oil products in thousand barrels per day from 1988 to 2008

\begin{tabular}{|c|c|c|c|c|c|}
\hline Year & Gas oil & Fuel oil & Gasoline & Kerosene & Liquid gas \\
\hline 1988 & 37.63 & 25.93 & 16.18 & 15.43 & 4.84 \\
\hline 1989 & 36.30 & 24.44 & 18.40 & 15.73 & 5.12 \\
\hline 1990 & 37.53 & 24.29 & 16.78 & 16.28 & 5.13 \\
\hline 1991 & 37.63 & 23.97 & 16.38 & 16.78 & 5.25 \\
\hline 1992 & 36.44 & 22.90 & 17.11 & 18.25 & 5.31 \\
\hline 1993 & 36.05 & 23.37 & 17.62 & 17.65 & 5.30 \\
\hline 1994 & 35.83 & 24.22 & 18.01 & 17.09 & 4.84 \\
\hline 1995 & 35.77 & 24.47 & 17.98 & 16.87 & 4.91 \\
\hline 1996 & 35.58 & 24.00 & 18.34 & 17.06 & 5.02 \\
\hline 1997 & 36.95 & 20.99 & 20.07 & 16.70 & 5.29 \\
\hline 1998 & 33.69 & 27.78 & 19.00 & 15.59 & 3.94 \\
\hline 1999 & 36.36 & 22.48 & 21.18 & 15.68 & 4.30 \\
\hline 2000 & 35.73 & 23.72 & 20.74 & 15.50 & 4.31 \\
\hline 2001 & 35.88 & 20.61 & 22.40 & 15.96 & 5.15 \\
\hline 2002 & 36.72 & 16.17 & 25.37 & 15.95 & 5.78 \\
\hline 2003 & 36.34 & 14.68 & 27.94 & 15.59 & 5.47 \\
\hline 2004 & 31.96 & 16.35 & 30.76 & 15.98 & 4.96 \\
\hline 2005 & 33.60 & 17.57 & 30.06 & 13.62 & 5.16 \\
\hline 2006 & 37.04 & 18.00 & 31.26 & 10.52 & 3.19 \\
\hline 2007 & 37.82 & 21.32 & 26.11 & 10.49 & 4.26 \\
\hline 2008 & 34.68 & 25.06 & 28.54 & 9.66 & 2.06 \\
\hline Average & 35.98 & 22.01 & 21.92 & 15.35 & 4.74 \\
\hline
\end{tabular}

Source of Data: Central Bank of Iran

\section{Literature review}

\subsection{Theoretical background}

The relationship between energy consumption and economic growth has been theoretically investigated through two main different approaches. In the neoclassical growth models, energy is simply considered as an intermediate input of production. According to Bartleet and Gounder [5], proponents of this view think that there are some mechanisms by which economic growth could remain in spite of a limited source of energy resources. The underlying explanation for this is built upon the possibility of technological change and substitution of other physical inputs for energy to use existing energy resources efficiently, and to generate renewable energy resources that are not subject to binding supply constraints. Accordingly, energy is merely one of the non-essential inputs in production process. In other words, the advocates of this theory support the 'neutrality hypothesis' and 'conservation hypothesis'. These hypotheses imply that energy supply restrictions might not have any harmful effect on economic growth. Thus, the government can simultaneously adopt the energy conservation and economic growth policies.

On the other hand, the ecological economic theory states that energy consumption is a limiting factor to economic growth, especially in modern economies. Ecological economists judge that technological progress and other physical inputs could not possibly substitute the vital role of energy in production process. They even consider energy as the prime source of value because other factors of production such as labour and capital cannot perform without energy. The promoters of this perspective protect the so-called 'growth hypothesis', and hence, advise that any shock to energy supply will ultimately have a negative impact on economic growth. As a result, they are against the energy conservation policies [22].

Considering the above theories, apart from labor and capital, energy is considered as a key factor of production. It follows that production can be considered as a function of a combination of inputs, i.e., labor, capital and energy.

$Q=f(K, L, E)$ 
where, Q, K, L, and E are gross domestic product, capital, labor and energy respectively. It is also assumed that there is a direct correlation between the consumption level of these variables and production level. Formally, it can be expressed as follows:

$$
\frac{\partial Q}{\partial K}>0, \frac{\partial Q}{\partial L}>0, \frac{\partial Q}{\partial E}>0
$$

$\mathrm{E}$ is energy carriers including oil products, gas, electricity, coal, and so on. On the other hand, the energy consumption is the inverse function of its price and energy price changes have an important effect on energy consumption and, subsequently, its GDP [20].

In recent theories of economic growth, the energy factor has been introduced into different models with varying degrees of significance. Stern and Cleveland [21] have investigated the factors affecting the relation between energy consumption and economic activities. They have represented the general outline of a production function as follows:

$\left(Q_{1} \ldots Q_{n}\right)=f\left(A, X_{1} \ldots X_{n}, E_{1} \ldots \mathrm{E}_{\mathrm{n}}\right)$

where, Q1 is different goods and services; X1 represents different inputs such as capital, labor etc; E1 is different energy inputs like oil products and coal; and finally A constitutes technological condition having been defined as the index of total factor productivity (TFP). In this function, the relationship between energy and production can be influenced by substitutability between energy and other inputs, technological changes and changes in energy combination. The relationship between energy and production can also be influenced by a change in combination of other inputs, e.g. any move away from labor-intensive economy to capital-intensive economy. Therefore, there is mounting evidence suggesting the effect of energy consumption on economic growth.

\subsection{Empirical studies}

Despite numerous studies of the empirical relationship between energy consumption, energy consumption in different economic sectors, different energy carrier consumption and gross domestic product, few, if any, studies have investigated the relationship between the consumption of different oil products and economic growth, either domestically or internationally. According to the findings of empirical studies, for some countries this relationship is claimed to be bidirectional; for others no relationship has been found; and on some occasions a unidirectional causality running from energy consumption to economic growth, but not vice versa, has been established. Surprisingly enough, in some cases, this relationship has moved from economic growth toward energy consumption, but not the other way round. Therefore, the results are still mixed, and whether energy consumption Granger causes economic growth or the reverse is still to be debated. The non-consensus on the causality between energy and output might be because different economies have different energy consumption patterns as well as different sources of energy which might have varying impacts on economic growth. In this section, we are only concerned with the relationship between the consumption of different energy carriers such as oil products, electricity, natural gas, solid fuels and economic growth, sidestepping other studies ${ }^{1}$.

Abrishami and Mostafaei [1] have examined the relationship between the consumption of major oil products and economic growth from 1959 to 1999. The results show that there is no Granger causality from the consumption of oil products to gross domestic product in the short term, but there is a weak causal relationship from the consumption of oil products to GDP in the long-run. Results also confirm a causal relation from GDP to oil products consumption in the long-run.

Applying Toda-Yamamoto method and error correction model, Arman and Zare [3] have considered the causality relationship between the total consumption of energy and energy carriers, and economic growth from 1967 to 2002. They have found a unidirectional Granger causality running from the total consumption of energy, oil product consumption and electricity consumption to economic growth; and a unidirectional causality running from economic growth to the consumption of natural gas and solid fuels. The results of the application of the error correction model also indicate that there is a bidirectional Granger causality relationship between electricity consumption and economic growth both in the short-run and in the long-run and there is also a unidirectional Granger causality running from economic growth to natural gas consumption only in the long-run.

Applying Hsiao causality test, Najjarzadeh and Abbas Mohsen [16] have examined the causality relationship between energy carriers and Iran's economic sectors between 1971 and 2002. Results suggest a bidirectional causality relationship between the total consumption of oil products and economic growth.

Behboodi et al. [6] have also investigated the relationship between energy consumption in domestic and commercial sectors and economic growth with respect to the final demand for energy, on the one hand, and the relationship between energy consumption in industry, agriculture and transportation with respect to the intermediate demand for energy, on the other hand. In doing so, they have applied Granger causality model and error correction model. Results suggest a

\footnotetext{
${ }^{1}$ For a detailed discussion of the relationship between energy consumption and economic growth, see Odhiambo [19] and Behboodi et al. [6].
} 
unidirectional causality running from the final demand for energy to economic growth and a bidirectional causality relationship between the intermediate demand for energy and economic growth.

Applying vector error correction model, Zamani [24] has examined the relationship between gross domestic product and industry's and agriculture's value added and kinds of energy carriers from 1976 to 2003 in Iran. His findings confirm a unidirectional causality running from gross domestic product to the total consumption of energy, gas and oil products, on the one hand, and one more unidirectional causality running from the total consumption of energy, electricity, gas and oil products to the industry's value added, on the other hand. According to his findings, agriculture has a bidirectional relationship with the total consumption of energy, oil products and electricity.

Asgharpoor et al. [4] have considered the relationship between the total consumption of natural gas and economic growth, focusing on the structural break during the period of 1967-2006. For determining endogenous structural changes, they have applied Gregory-Hansen cointegration test and Zivot-Andrews unit root test (1993), with results revealing a long-run positive relation between the total consumption of natural gas and economic growth.

Numerous studies have been carried out on the relationship between energy consumption and economic growth overseas, some of which are briefly discussed in what follows.

Altinay and Karagol [2] have examined the relationship between electricity consumption and economic growth, drawing on relevant data on these two variables from 1950 to 2000. Using the Zivot-Andrews unit root test, they have found the breakpoint for each of electricity consumption and gross domestic product time series. For examining the causality relationship between these two variables, they have applied two methodologies in Granger causality test: (I) Dolado and Lutkepohl test which uses the vector autoregression in levels and (II) the standard Granger causality test. Results suggest a unidirectional causality running from electricity consumption to economic growth.

Lee and Chang [12] have also examined the relationship between energy consumption and each of energy carriers, and gross domestic product in the context of Taiwan during the period of 1954-2003. The results of their study suggest that with structural break taken into account, there is a unidirectional causality running from oil consumption to gross domestic product.

Yoo and Koo [23] have investigated the relationship between nuclear energy consumption and economic growth. The results of the causality test show a bidirectional causality relationship between nuclear energy consumption and economic growth in Switzerland, a unidirectional causality running from economic growth to nuclear energy consumption in France and Pakistan as well as a unidirectional causality running from energy consumption to economic growth in Korea. No causality relationship, however, has been found between these two variables in the context of Argentina and Germany.

Fatai et al. [8] have examined the relationship between the consumption of different kinds of energy carriers, employment and economic growth in New Zealand and Australia during the period of 1960-1990, using JohansenJuselius tests and Granger causality test. As far as New Zealand is concerned, the results of the standard Granger causality test suggest no Granger causality relationship between oil, gas and coal consumption and gross domestic product. On the other hand, the results of the standard Granger causality test and error correction model suggest that in Australia there is a unidirectional Granger causality running from real gross domestic product to the consumption of electricity and to the total consumption of energy.

Narayan and Smyth [18] have investigated the relationship between electricity consumption, employment and real income in Australia from 1966 to 1999, using vector error correction model. Their findings point to a long-run unidirectional causality running from employment and income to electricity consumption.

Lee and Chang [12] have also investigated the relationship between gross domestic product, and the total consumption of energy and different types of energy including oil, electricity, gas and coal in Taiwan during the period of 19542003. In this study, they have used cointegration test, taking into account structural break. Their findings indicate a unidirectional causality running from gross domestic product to energy consumption.

As can be seen from the above literature review, despite many studies investigating the causal relationship between energy carries - i.e., natural gas, electricity, solid fuels and oil products in general - and the total energy consumption and economic growth both in Iran and overseas, the causal relationship between the consumption of different oil products and economic growth in Iran has not received the attention it deserves, and there is a lack of empirical studies that investigate this causal relation. In light of the recent implementation of subsidy reform plan and the elimination of subsidies for energy carrier prices and, in particular, for oil product prices in Iran, and the pressing need for providing clearer and more effective policy guidelines to help advance the plan, the present study is an attempt to explore the relationship between the consumption of different oil products and economic growth. 


\section{Data, methodology and empirical results}

\subsection{Data collection}

In this paper, I have examined the relationship between the consumption of different oil products and Iran's economic growth, using the quarterly data from 1988 to 2008. The data used in this study have been collected from energy balance sheets relating to this period of time and from the websites of Statistical Center of Iran and Iran's Central Bank. For analyzing the data, I have applied the vector error correction model.

\subsection{Methodology}

The model used for the purposes of this research is based on related studies in this area. Therefore, accounting for different types of oil products, I have estimated different vector error correction models.

Generally, the autoregressive model with $\mathrm{N}$ endogenous variables and the $\mathrm{K}$ lags of each variable can be represented as follows:

$X_{t}=\Pi_{1} X_{t-1}+\Pi_{2} X_{t-2}+\ldots+\Pi_{K} X_{t-K}+U_{t}$

where, $X$ is the vector of endogenous variables and its lags. The vector $X$ in estimated VAR models of this paper includes the logarithm of real GDP and natural logarithm of various oil products. The variables GOC, GLC, FOC, BOC and LGC represent the amount of gas oil consumption, gasoline consumption, fuel oil consumption, kerosene consumption and liquid gas consumption, respectively. Granger causality relationship between various oil products consumption and economic growth is analyzed in separate VAR models. That's because considering several oil products in the same model, would significantly decrease the degree of freedom.

In order to estimate VAR models, we should initially examine the stationarity of variables and determine optimum lag length. As regards the importance of variables stationarity, one can say if variables are stationary, then using a simple VAR model would be appropriate. But if variables were non-stationary, we perform cointegration test after selecting optimal lag length. If variables are not cointegrated, then we will estimate the model by using the first difference of variables, as follows:

$\Delta X_{t}=\Gamma_{1} \Delta X_{t-1}+\Gamma_{2} \Delta X_{t-2}+\ldots+\Gamma_{k-1} \Delta X_{t-k+1}+\Pi_{K} X_{t-K}+U_{t}$

If variables are cointegrated, then we can use vector error correction model as below:

$\Delta X_{t}=\Gamma_{1} \Delta X_{t-1}+\Gamma_{2} \Delta X_{t-2}+\ldots+\Gamma_{k-1} \Delta X_{t-k+1}+\Pi_{K} X_{t-K}+U_{t}$

Where,

$i=1,2, \ldots, k \quad \Gamma_{i}=-I+\Pi_{1}+\Pi_{2}+\ldots+\Pi_{i}$ and $\Pi=-\left(I-\Pi_{1}-\Pi_{2}-\ldots-\Pi_{k}\right)$.

This way of specifying the system contains information on both the short and long-run adjustment to changes in $\mathrm{X}$, via the estimates of $\Gamma_{i}$ and $\Pi$, respectively. $\Pi=\alpha \beta^{\prime}$, where $\alpha$ represents the speed of adjustment to disequilibrium and $\beta$ is a matrix of long-run coefficients. $I$ is a unit matrix [9].

Since the error correction term and all $\Delta X_{t-i}$ will be stationary, by using common statistics, we can use statistic inference for any of variables except those appearing in the cointegrating vector. Therefore if $I(d)$ variables were not cointegrated within the system, it is better to use the difference of variables. Otherwise and by using variables level, the Granger causality tests conducted on I(d) variables, would not have Standard F distribution. If we incorporate the difference of the variables in the VAR model, then we could use standard F test for Granger causality test. So accurate determination of whether $\mathrm{I}(\mathrm{d})$ variables are cointegrated or not, is very important [7].

Testing for the existence of a statistical relationship among the three variables is carried out in three steps. The first step is to verify the order of integration of the variables since the causality tests are valid if the variables have the same order of integration. Standard test for the presence of a unit root based on the work of Dickey and Fuller is used to investigate the degree of integration of the variables used in the empirical analysis. The second step involves testing for cointegration using the Johansen maximum likelihood approach. The Johansen-Juselius estimation method is based on the error-correction representation of the VAR model with Gaussian errors. Evidence of cointegration rules out the possibility of the estimated relationship being spurious. So long as the variables have common trend, causality, in the Granger sense and not in the structural sense, must exist in at least one direction. Although cointegration implies the presence of Granger causality it does not necessarily identify the direction of causality between variables. This temporal Granger causality can be captured through the vector error-correction model derived from the long-run cointegrating vectors. Thus, the third step involves utilization of the vector error-correction modeling and testing for exogeneity of variables. Engle and Granger show that in the presence of cointegration, there always exists a corresponding errorcorrection representation which implies that changes in the dependent variable are a function of the level of disequilibrium in the cointegrating relationship, captured by the error-correction term (ECT), as well as changes in other 
explanatory variables. Thus, through ECT, the VECM modeling establishes an additional way to examine the Granger causality ignored initially from the Granger-Sims tests. The Wald test applied to the joint significance of the sum of the lags of each explanatory variable and the t-test of the lagged error-correction term will imply statistically the Granger exogeneity or endogeneity of the dependent variable. The non-significance of ECT is referred as a long-run noncausality which is equivalent to that the variable is weakly exogenous with respect to long-run parameters. The absence of short-run causality is established from the non-significance of the sums of the lags of each explanatory variable. Finally, the non-significance of all the explanatory variables including the ECT term in the VECM indicates the econometric strong exogeneity of the dependent variable, which is the absence of Granger causality [11].

\subsection{Unit root tests}

To ensure the stationarity of variables, in this study, I use Augmented Dicky-Fuller unit root test (ADF). In this test, the null hypothesis indicates non-stationarity and alternative hypothesis expresses stationarity.

As in Table 2, based on Dicky-Fuller test for all variables, the stationarity is obtained after one difference, so all Variables are $\mathrm{I}(1)$.

Table2: Augmented Dicky-Fuller unit root test results

\begin{tabular}{|c|c|c|c|c|c|c|c|}
\hline \multirow{2}{*}{ Variable } & \multirow{2}{*}{$\begin{array}{l}\text { Dicky- } \\
\text { Fuller } \\
\text { statistics }\end{array}$} & \multicolumn{3}{|c|}{ Critical values of Mackinnon } & \multirow{2}{*}{ Trend } & \multirow{2}{*}{ Intercept } & \multirow{2}{*}{$\begin{array}{l}\text { Number of } \\
\text { lags }\end{array}$} \\
\hline & & $1 \%$ & $5 \%$ & $10 \%$ & & & \\
\hline $\log (G D P)$ & -2.24 & -4.08 & -3.47 & -3.16 & $T$ & $C$ & 4 \\
\hline $\mathrm{D}(\log (\mathrm{GDP}))$ & -4.89 & -3.51 & -2.89 & -2.59 & - & $C$ & 3 \\
\hline $\log (\mathrm{GOC})$ & -2.77 & -4.08 & -3.47 & -3.16 & $T$ & $C$ & 4 \\
\hline $\mathrm{D}(\log (\mathrm{GOC}))$ & -5.87 & -3.51 & -2.89 & -2.59 & - & $C$ & 5 \\
\hline $\log (\mathrm{FOC})$ & -2.82 & -4.08 & -3.47 & -3.16 & $T$ & $C$ & 5 \\
\hline $\mathrm{D}(\log (\mathrm{FOC}))$ & -3.44 & -2.59 & -1.94 & -1.61 & - & - & 5 \\
\hline $\log (\mathrm{GLC})$ & -2.69 & -4.08 & -3.47 & -3.16 & $T$ & $C$ & 5 \\
\hline $\mathrm{D}(\log (\mathrm{GLC}))$ & -5.79 & -3.51 & -2.89 & -2.59 & - & $C$ & 4 \\
\hline $\log (\mathrm{BOC})$ & -1.87 & -3.51 & -2.89 & -2.59 & - & $C$ & 4 \\
\hline $\mathrm{D}(\log (\mathrm{BOC}))$ & -19.34 & -2.59 & -1.94 & -1.61 & - & - & 2 \\
\hline $\log ($ LGC $)$ & -0.81 & -2.59 & -1.94 & -1.61 & - & - & 5 \\
\hline $\mathrm{D}(\log (\operatorname{LGC}))$ & -2.41 & -2.59 & -1.94 & -1.61 & - & - & 3 \\
\hline
\end{tabular}

Source: Research findings

\subsection{Lag length selection}

Having examined the variables' stationarity, equation 4 was estimated by vector autoregressive method to determine the optimal lags of the model for investigating the long-run relationship between variables and afterwards the optimal lag for each VAR models was determined. Due to limited number of observations in this study, the maximum lag is considered equal to 4 and to determine optimal lag, I used Akaike's information criterion (AIC), Schwarz's Bayesian criterion (SBC), Hannan-Queen information criterion (HQC) and maximum likelihood estimation (MLE) method. Results show that optimal lag in all VAR models is equal to 4.

\subsection{Cointegration test results}

The cointegration test between Logarithm of real GDP and the logarithm of each of oil products consumption are done using vector error correction model and Johansson- Joselius process. To use Johansson- Joselius test, it is necessary to determine the number of cointegrating vectors. So doing, I use maximum eigenvalue statistic and Trace statistic. In order to examine the cointegration test, I focus on five cases of interest delineated according to how the deterministic components are specified: without intercept and time trend, with restricted intercept and no time trend, unrestricted intercept and no time trend, unrestricted intercept and restricted time trend, unrestricted intercept and unrestricted time trend. I begin by more unrestricted model, the fifth model, and test the significance of restricted time trend by estimation of it. If the restricted time trend is not significance, then I consider the fourth model and after estimating it, test the existence of a restricted time trend and so on to select the most proper model [10]. Having selected the appropriate model, using maximum eigenvalue and Trace tests, I determine the number of cointegrating vectors. 
Appropriate selected model for different models and the number of cointegrating vectors corresponding to the selected model are given in table 3 .

Table3: Results of Trace and Maximum Eigenvalue Tests

\begin{tabular}{llll}
\hline VAR model & Selected Case & Test & Number of Cointegrating Vectors \\
\hline \multirow{2}{*}{ Fuel oil consumption } & $I I I$ & Trace & 1 \\
& $I I$ & Maximum Eigenvalue & 1 \\
gasoline consumption & $I V$ & Trace & 1 \\
& & Maximum Eigenvalue & 1 \\
Kerosene consumption & $I V$ & Trace & 0 \\
\multirow{2}{*}{ LPG consumption } & $I V$ & Maximum Eigenvalue & 0 \\
& & Trace & 0 \\
Fuel oil consumption & Maximum Eigenvalue & 0 \\
& & Trace & 0 \\
\hline
\end{tabular}

Source: Research findings

\subsection{Granger causality test}

In this section, I examine the long-run and short-run Granger causality between oil products consumption and economic growth. In order to study the Granger causality among the variables of oil products consumption and economic growth, I use error correction model (ECM) and equations (7) and (8) in which LOPC could be the logarithm of gasoil and fuel oil consumption. According to Mehrara [13], the most popular method for Granger causality tests, is based on the VECM if variables are cointegrated. The VECM can avoid shortcomings of the VAR based models in distinguishing between a long-run and a short-run relationship among the variables. Theoretically, cointegration implies the existence of causality between variables, but it does not indicate the direction of the causal relationship. The VECM is estimated by using the following VAR model:

$$
\begin{aligned}
& D L G D P=\alpha+\sum_{i=1}^{4} b_{i} D L G D P_{t-i}+\sum_{i=1}^{4} c_{i} D L O P C_{t-i}+\sigma_{1} E C T_{t-1}+\varepsilon_{1 t} \\
& D L O P C_{j}=\alpha+\sum_{i=1}^{4} \beta_{i} D L G D P_{t-i}+\sum_{i=1}^{4} \gamma_{i} D L O P C_{t-i}+\sigma_{2} E C T_{t-1}+\varepsilon_{2 t}
\end{aligned}
$$

In equation 7 and 8 , the long-run causality can be tested by looking at the significance of the speed of adjustment, which is the coefficient of the error correction term. This is easily based on the t statistic. Specifically, we must test the following null hypotheses:

H0: $\sigma 1=0$ or Granger non - causality in the long - run

$\mathrm{H} 0: \sigma 2=0$ or Granger non - causality in the long - run

Yet in order to examining the Granger causality between variables of logarithms of gasoline, kerosene and liquid gas consumption which are not cointegrated with logarithm of GDP, we use first order difference of these variables, a VAR model as Equations 9 and 10 is formed and Granger causality tests are performed.

$$
\begin{aligned}
& D L G D P=\alpha+\sum_{i=1}^{4} b_{i} D L G D P_{t-i}+\sum_{i=1}^{4} c_{i} D L O P C_{t-i}+\varepsilon_{1 t} \\
& D L O P C_{j}=\alpha+\sum_{i=1}^{4} \beta_{i} D L G D P_{t-i}+\sum_{i=1}^{4} \gamma_{i} D L O P C_{t-i}+\varepsilon_{2 t}
\end{aligned}
$$

The equations (9) to (10) are first estimated by OLS method, and then we apply the $\chi^{2}$ test for the joint significance of the coefficients on the lagged terms in the unrestricted models. Specifically, the following null hypotheses are necessarily tested:

H0: $\sum_{i=1}^{4} c_{i}=0$ or economic growth does not Granger cause oil products consumption

H0: $\sum_{i=1}^{4} \beta_{i}=0$ or oil products consumption does not Granger cause economic growth 
Table 4 shows the results of short-run Granger causality tests by an error correction model as equations 7 and 8 . In equation 7 , the dependent variable is the logarithm of GDP and in equation 8 , the dependent variable is the logarithm of gas oil and fuel oil consumption. The results show that in short-run, regarding the insignificance of DLGDPj coefficients, a one-way causality relationship from gas oil and fuel oil consumption to economic growth does not exist. Also regarding the significance of DLGDPj coefficients, at $10 \%$ significance level, there is a weak one-way relationship from economic growth to fuel oil.

The $t$ statistic related to the coefficient of lagged error correction term $\left(E C T_{t-1}\right)$ for gas oil and fuel oil models is shown in table 5. The results show that in long-run due to significance of lagged error correction term $(\sigma 1$ and $\sigma 2)$ in fuel oil model, there is a two-way Granger causality relationship between fuel oil consumption and economic growth. In the other hand in gas oil model, only coefficient for error correction of equation 8 is significant, which demonstrate this causality is one-way in long-run and its direction is from economic growth to consumption of gas oil.

Granger causality test results for equations 9 and 10 are presented in table 6. According to these tests, consumption of gasoline, kerosene and liquid gas are not stimulating economic growth. On the other hand, economic growth is the Granger causality for gasoline consumption and there is a weak causality from economic growth to the consumption of kerosene. Also Economic growth was not Granger cause of LPG consumption. In other words, there exist a one-way Granger causality from economic growth to gasoline consumption and weak one-way Granger causality from economic growth to the consumption of kerosene. But, there is no causality between economic growth and consumption of liquid gas.

Table 4: Results of short-run Granger causality tests among GDP and consumption of gas oil and fuel oil

\begin{tabular}{lllll}
\hline Direction of causality & DLGOC $\rightarrow$ DLGDP & DLFOC $\rightarrow$ DLGDP & DLGDP $\rightarrow$ DLGOC & DLGDP $\rightarrow$ DLFOC \\
\hline \multirow{2}{*}{ The null hypothesis } & $\sum_{i=1}^{4} c_{i}=0$ & $\sum_{i=1}^{4} c_{i}=0$ & $\sum_{i=1}^{4} \beta_{i}=0$ & $\sum_{i=1}^{4} \beta_{i}=0$ \\
& 1.41 & 3.85 & 16.57 & 7.86 \\
$\chi^{2}$ Statistics (prob.) & $(0.8432)$ & $(0.4272)$ & $(0.0023)$ & $(0.0970)$ \\
\hline
\end{tabular}

Source: Research findings

Table 5: Long-run Granger causality tests results, using error correction model

\begin{tabular}{|c|c|c|c|}
\hline Model & First VAR model & Gas oil consumption & Second VAR model: Fuel oil consumption \\
\hline The null hypothesis & $\sigma 1=0$ & $\sigma 2=0$ & $\sigma 2=0$ \\
\hline t-Statistics & 0.36 & 4.01 & 3.77 \\
\hline
\end{tabular}

Source: Research findings

Table 6: The results of short-run Granger causality tests, using VAR model by first order difference of variables

\begin{tabular}{lllllll}
\hline $\begin{array}{l}\text { Direction } \\
\text { of } \\
\text { causality }\end{array}$ & $\begin{array}{l}\mathrm{DLGLC} \rightarrow \mathrm{DL} \\
\mathrm{GDP}\end{array}$ & $\begin{array}{l}\mathrm{DLGDP} \rightarrow \mathrm{DL} \\
\mathrm{GLC}\end{array}$ & $\begin{array}{l}\mathrm{DLBOC} \rightarrow \mathrm{DL} \\
\mathrm{GDP}\end{array}$ & $\begin{array}{l}\text { DLGDP } \rightarrow \mathrm{DL} \\
\mathrm{BOC}\end{array}$ & $\begin{array}{l}\text { DLLLGC } \rightarrow \mathrm{DL} \\
\text { GDP }\end{array}$ & $\begin{array}{l}\text { DLGDP } \rightarrow \mathrm{DL} \\
\text { LGC }\end{array}$ \\
\hline $\begin{array}{l}\text { The null } \\
\text { hypothesi }\end{array}$ & $\sum_{i=1}^{4} c_{i}=0$ & $\sum_{i=1}^{4} \beta_{i}=0$ & $\sum_{i=1}^{4} c_{i}=0$ & $\sum_{i=1}^{4} \beta_{i}=0$ & $\sum_{i=1}^{4} c_{i}=0$ & $\sum_{i=1}^{4} \beta_{i}=0$ \\
$\mathrm{~s}$ & 49.58 & 1.10 & 8.64 & 3.97 & 0.72 \\
$\chi^{2}$ Statist & 4.17 & $(0.0000)$ & $(0.8938)$ & $(0.0706)$ & $(0.4099)$ & $(0.9488)$ \\
ics (prob.) & $(0.3840)$ & & &
\end{tabular}

Source: Research findings

\section{Conclusion}

In light of the recent implementation of subsidy reform plan and the elimination of subsidies for oil product prices in Iran, the present study examined the relationship between the consumption of different oil products and economic growth, using quarterly data during the period 1988-2008. I have used the time series data of the logarithm of real GDP and the logarithm of consumption of different oil products. Applying the vector autoregressive model, I analyzed the Granger causality relationship between the consumption of each of different oil products and economic growth separately. In our estimated VARs, each oil product is analyzed de per se, as including several ones in the same VAR would dramatically decrease the degrees of freedom. For estimating the vector autoregressive models, I, firstly, determined the stationarity of the variables and, then, specified the optimum lag length of the models. The cointegration tests showed that there was a cointegrating vector only in the case of the relationship between fuel oil and gas oil 
consumption and gross domestic product. Only in these cases the error correction model was used to determine the causality relationship while in other cases of variables lacking a cointegrating relationship, vector autoregressive models were estimated by means of first difference of the variables.

Results reveal that the consumption of none of the oil products stimulates economic growth in the short-run. Economic growth, however, is shown to be the Granger cause of gas oil and gasoline consumption. A weak Granger causality relationship can also be found between economic growth and fuel oil and kerosene consumption. No relationship can be established between economic growth and liquid gas consumption. In the long run, there is a bidirectional Granger causality relationship between fuel oil consumption and economic growth and a unidirectional Granger causality running from economic growth to gas oil consumption, though. Furthermore, there is no relation between the consumption of other products and economic growth.

The results suggest that the reduction of oil products consumption, except fuel oil consumption, due to price increases resulting from removal of subsidies, will not negatively affect the economic growth and, hence, the government can pursue the subsidy reform plan on oil products without decelerating economic growth. However, the policy of saving fuel oil consumption should be done with caution due to the existence of long-run causality from the consumption of this product to economic growth.

\section{References}

[1] Abrishami, Hamid and Mostafaei (2001), "Investigating the relationship between oil products consumption and economic growth in Iran"” Knowledge and Development Journal/ No. 14.

[2] Altinay, G., Karagol, E., (2005), Electricity consumption and economic growth: evidence from Turkey. Energy Economics 27, 849-856

[3] Arman, Seyyed Aziz and Zare, Rohollah (2005), Investigating the Granger causality relationship between energy consumption and economic growth in Iran between 1967-2002, Iranian Quarterly Economic Research, No. 24, pp. 117-143.

[4] Asgharpoor, Hossein, Behboodi, Davoodand Qazvinian, Mohammad Hassan (2009), Structural break, electricity consumption and economic growth in Iran, Mofid Economic Letter, No. 72, Summer edition, pp. 75-100.

[5] Bartleet, M., and Gounder, R., (2010). Energy consumption and economic growth in New Zealand: Results of trivariate and multivariate models. Energy Policy, 38, 3508-3517.

[6] Behboodi, Davood, Parviz Mohammadzadeh and Savad Jebraeili (2009), "Examining energy consumption and GDP in developed and developing countries", Iranian Quarterly for Economic Studies/ 6th year/ No. 33/ pp. 1-21.

[7] Enders, W., 1995. Applied Econometric Time Series. Wiley, New York.

[8] Fatai, K. et al. (2004). Modeling the Causal Relationship between Energy Consumption and GDP in New Zealand, Australia, India, Indonesia, the Philippines and Thailand. Mathematics and Computer in Simulation. No.64, PP.431-445.

[9] Harris, R. I. D. and R. Sollis (2003). Applied time series modelling and forecasting.Chichester: J. Wiley.

[10] Heij et al. (2004), Econometric Methods with Applications in Business and Economics, Oxford University Press Inc., New York.

[11] Hondroyiannis G.et al (2002), Energy consumption and economic growth: assessing the evidence from Greece, Energy Economics 24(2002) 319_336.

[12] Lee, Ch. And Chang Ch. (2005), Structural Breaks, Energy Consumption and Economic Growth Revisited: Evidence from Taiwan, Energy Economics, No. 27, PP.857-872.

[13] Mehrara, M., 2007. Energy consumption and economic growth: the case of oil exporting countries. Energy Policy 35, $2939-2945$.

[14] Ministry of Energy, Department of Energy (2006), energy balance sheet, http://pep.moe.org.ir.

[15] Ministry of Energy, Department of Energy (2008), energy balance sheet.

[16] Najjarzadeh, R. and Abbas Mohsen, A. (2004), the relationship between energy consumption and economic growth in Iran Economic sectors, Quarterly Energy Economics Review, 1(2), pp. 61-80.

[17] Narayan, P.K., Smyth, R., (2005). Electricity consumption, employment and real income in Australia: evidence from multivariate Granger causality tests. Energy Policy, 33, pp.1109-1116.

[18] Odhiambo, Nicholas M. (2009), Energy consumption and economic growth nexus in Tanzania: An ARDL bounds testing approach, Energy Policy 37, 617-622.

[19] Qazvinian, Hassan (2007), Investigating structural break with respect to the relationship between energy consumption and economic growth in Iran, MA thesis, Tabriz University, Faculty of Humanities and Social Sciences.

[20] Stern DI, Cleveland CJ. (2004), Energy and Economic Growth. Rensselaer Polytechnic Institute, Rensselaer Working Papers in Economics No. 0410 .

[21] Thanh Binh, Phung (2011), Energy Consumption and Economic Growth in Vietnam: Threshold Cointegration and Causality Analysis, International Journal of Energy Economics and Policy, Vol. 1, No. 1, 2011, pp. 1-17

[22] Yoo, S.H., Ku, S.J(2009), Causal relationship between nuclear energy consumption and economic growth: A multi-country analysis, Energy Policy, No.37, PP.1905-1913.

[23] Zamani, M., (2007). Energy consumption and economic activity in Iran. Energy Economics, 29(6), pp.1135-1140. 